\begin{tabular}{c} 
International Journal of Engineering \& Technology, 7 (3.11) (2018) 48-51 \\
International Journal of Engineering \& Technology \\
SPC \\
Website: www.sciencepubco.com/index.php/IJET \\
Research paper \\
\hline
\end{tabular}

\title{
Structural Studies of Zno Nanostructures on Porous Silicon: Effect of Post-Annealing Temperature
}

\author{
Kevin Alvin Eswar ${ }^{1,2,3 *}$, Mohd Husairi Fadzillah Suhaimi ${ }^{2,3}$, Muliyadi Guliling ${ }^{1,3}$, Zuraida Khusaimi ${ }^{2,3}$ \\ Mohamad Rusop ${ }^{2}$ and Saifollah Abdullah ${ }^{2,3}$ \\ ${ }^{I}$ Faculty of Applied Science, Universiti Teknologi MARA, Sabah Branch Tawau Campus, 91032 Tawau, Malaysia \\ ${ }^{2}$ NANO-SciTech Centre, Institute of Science, Universiti Teknologi MARA, 40450 Shah Alam, Selangor, Malaysia \\ ${ }^{3}$ Faculty of Applied Sciences, Universiti Teknologi MARA, 40450 Shah Alam, Selangor, Malaysia \\ *Corresponding author E-mail:kevinalvin86@gmail.com
}

\begin{abstract}
$\mathrm{ZnO}$ Nanostructures have been successfully deposited on of Porous silicon (PSi) via wet colloid chemical approach. PSi was prepared by electrochemical etching method. ZnO/PSi thin films were annealed in different temperature in the range of $300{ }^{\circ} \mathrm{C}$ to $700{ }^{\circ} \mathrm{C}$. Surface morphology studies were conducted using field emission scanning microscopy (FESEM). Flower-like structures of $\mathrm{ZnO}$ were clearly seen at annealing temperature of $500{ }^{\circ} \mathrm{C}$. The X-ray diffraction spectra (XRD) have been used to investigate the structural properties. There are three dominant peaks referred to plane (100), (002) and (101) indicates that $\mathrm{ZnO}$ has a polycrystalline hexagonal wurtzite structures. Plane (002) shows the highest intensities at annealing temperature of $500{ }^{\circ} \mathrm{C}$. Based on plane (002) analysis, the sizes were in range of $30.78 \mathrm{~nm}$ to 55.18. In addition, it was found that the texture coefficient of plane (002) is stable compared to plane (100) and (101).
\end{abstract}

Keywords: Structural properties; Flower-like ZnO; Porous silicon; Annealing temperature

\section{Introduction}

Metal oxide thin films have been extensively studied in the last few decades. Zinc oxide $(\mathrm{ZnO})$ is one of them. It becomes popular due to properties of a large exciton binding energy of $60 \mathrm{meV}$ and and a wide band gap $\left(\mathrm{E}_{\mathrm{g}}\right)$ of $3.37 \mathrm{eV}$ [1]. In addition, good chemical and thermal stability, non-toxic material and high transparency in room temperature are additional advantages in devices fabrication [2]. There are various structures of $\mathrm{ZnO}$ have been produced such as nanoparticles, nanorods, nanowires, nano-flower and honey-comb [3-6]. The structure are highly depends on the methods applied such as hydrothermal, RF sputtering, sol-gel synthesis and pulsed laser ablation [7]. Among them, hydrothermal is the most practical for cost-effective method. In addition this method is controllable and implemented in low temperature. In substrate selection, silicon is the most popular due to its abundance in the earth crust. However, large mismatch between $\mathrm{ZnO}$ and silicon make it very challenging to deposits $\mathrm{ZnO}$ on silicon surface [8,9]. As an alternative, modifications of silicon surface are required. The silicon surface modified into porous to make the surface contact become larger.

\section{Method}

Wet colloid chemical approach was employed to synthesis $\mathrm{ZnO}$ nanostructures on PSi. PSi was prepared using electrochemical etching. Then, the $\mathrm{ZnO}$ thin film was deposited on PSi using solgel spin coating method as a seeded. Flower-like $\mathrm{ZnO}$ nanostruc- tures were grown on PSi via simple hydrothermal method. Zinc nitrate hexahydrate $\left(\mathrm{Zn}\left(\mathrm{NO}_{3}\right)_{2} \cdot 6 \mathrm{H}_{2} \mathrm{O}\right)$ was used as starting material while the hexamethylenetetramine (HMTA) as a stabilizer and dionized water as a solvent. The molarities of precursor were maintained at $0.2 \mathrm{M}$. PSi substrate was immersed into the $\mathrm{ZnO}$ precursor at $90{ }^{\circ} \mathrm{C}$ for 4 hours. It was followed by post-annealing heat treatment. The temperatures were varied from $300{ }^{\circ} \mathrm{C}$ to $700{ }^{\circ} \mathrm{C}$. The field emission scanning microscopic (FESEM) was used to study the morphology of $\mathrm{ZnO}$ nanostructures. The structural property was investigated using X-ray diffraction (XRD) spectroscopy.

\section{Results and Discussion}

Surface morphologies were investigated using FESEM characterization. Fig.1 shows the FESEM images of PSi and $\mathrm{ZnO}$ nanostructures on seeded PSi. Samples were treated by different post-annealing temperature in range of $300{ }^{\circ} \mathrm{C}$ to $700{ }^{\circ} \mathrm{C}$. $\mathrm{ZnO}$ nanostructures were agglomerate when annealed at $300{ }^{\circ} \mathrm{C}$. The structures also cannot be identified. A flower-like structure has been produced at annealing temperature of $500{ }^{\circ} \mathrm{C}$. It can be seen that the nano-flower is combination of $\mathrm{ZnO}$ nanorod. It was merges with adjacent nanostructures at post annealing temperatures of $700{ }^{\circ} \mathrm{C}$ to form of hexagonal island-like structures. The FESEM result shows that, post annealing temperatures are highly affecting the growth of $\mathrm{ZnO}$ nanostructures. Suggested that colloidal of $\mathrm{ZnO}$ have been formed within the solution. Furthermore, the growth of $\mathrm{ZnO}$ nanostructures in different structures may occur during post-annealing. 

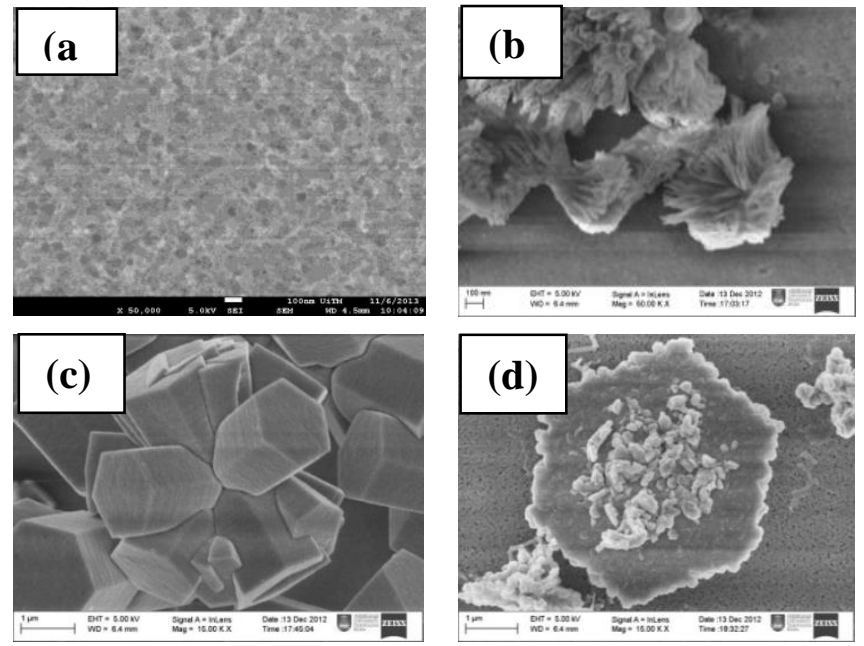

Fig. 1: FESEM images of (a) PSi and $\mathrm{ZnO}$ nanostructures deposited on seeded PSi with molarity of (b) $300{ }^{\circ} \mathrm{C}$, (c) $500{ }^{\circ} \mathrm{C}$ and (d) $700{ }^{\circ} \mathrm{C}$

Fig. 2 shows the $\mathrm{XRD}$ patterns of $\mathrm{ZnO}$ nanostructures treated with different annealing temperatures. Three dominant peaks referred to plane (100), (002) and (101) of ZnO nanostructures (JCPDS No: 36-1451) are appeared. Besides, plane of (102) and (100) are also seen in low intensity. This result indicates that $\mathrm{ZnO}$ has a polycrystalline hexagonal wurtzite structures [10]. Some impurities were found at annealing temperatures of $300{ }^{\circ} \mathrm{C}, 400{ }^{\circ} \mathrm{C}$ and $500^{\circ} \mathrm{C}$ which attributed by PSi substrate (JCPDS No: 17-0901) [11, 12]. This peak located in between plane of (100) and (002). The absence of PSi peak at annealing temperatures of $600{ }^{\circ} \mathrm{C}$ and $700{ }^{\circ} \mathrm{C}$ may be all surfaces may be covered by $\mathrm{ZnO}$ nanostructure at higher post-annealing temperature. Peak of plane (100) located at $32.08^{\circ}$ to $32.21^{\circ},(002)$ located at $34.70^{\circ}$ to $34.92^{\circ}$ and (101) located at $36.52^{\circ}$ to $36.72^{\circ}$. As can be seen, peak position slightly shifted to higher diffraction angle when annealing temperatures increased. The same phenomena have been found by Gao et. al. [13]. This is due to effect of strain within the crystalline.

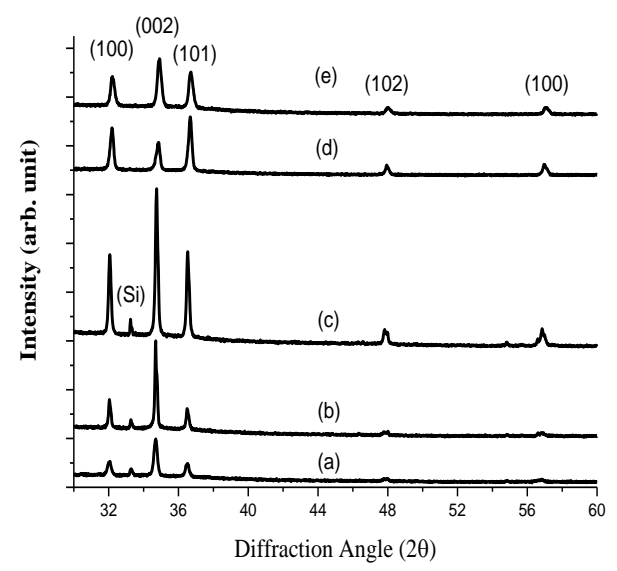

Fig. 2: $\mathrm{XRD}$ grating of $\mathrm{ZnO}$ nanostructures in different post-annealing temperatures of (a) $300{ }^{\circ} \mathrm{C}$, (b) $400{ }^{\circ} \mathrm{C}$, (c) $500{ }^{\circ} \mathrm{C}$, (d) $600{ }^{\circ} \mathrm{C}$ and (e) $700{ }^{\circ} \mathrm{C}$

Table 1 shows the plane distance, $d$ and crystallite size, $D$ in different annealing temperature. Plane distance of each plane in was calculated by Bragg's formula in Equation (1). Besides, an estimation of crystalline size, $D$ based on plane distance for each plane is also calculated using Equation (2). The parameter of $\lambda, d$, and $\theta$ represents sources wavelength, plane distance and peak position in radian. In this study, $0.154 \mathrm{~nm}$ of $\mathrm{Cu} \mathrm{K} \alpha$ radiation was used as sources [14].

$\lambda=2 d \sin \theta$
Scherrer's formula was used to estimate the crystalline size by using plane distance, $d$ for each plane. It can be represented by

$D=\frac{K \lambda}{\beta \cos \theta}$

where $D, K, \lambda, \beta$, and $\theta$ represents crystallite size, Scherer's constant (0.9), X-ray wavelength, FWHM and peak position respectively [11]. This equation shows that crystallite size, $D$ is directly influenced by the FWHM and peak position of each plane.

Table 1: FWHM of plane distance and crystallite size of plane (002) in different annealing temperatures

\begin{tabular}{|c|c|c|c|}
\hline $\begin{array}{c}\text { Annealing } \\
\text { Temperatures } \\
\left({ }^{\circ} \mathrm{C}\right)\end{array}$ & FWHM $\left({ }^{\circ}\right)$ & $\begin{array}{c}\text { Plane distance, } \\
D(\mathrm{~nm})\end{array}$ & Size (nm) \\
\hline 300 & 0.223 & 0.2581 & 37.02 \\
\hline 400 & 0.151 & 0.2581 & 55.18 \\
\hline 500 & 0.170 & 0.2578 & 49.1 \\
\hline 600 & 0.260 & 0.2569 & 32.11 \\
\hline 700 & 0.270 & 0.2566 & 30.78 \\
\hline
\end{tabular}

Generally, FWHM increases due to increase of due to increases of annealing temperatures. The increases of the FWHM are related to the decreases of crystallite size. The plane distance is highly dependent on peak position. The plane of (002) distance is consistent with Urgessa et al. by using high resolution transmission electron microscope [15].

Table 2 shows the lattice constant of ' $a$ ' and ' $c$ ', Zn-O bond length, $L$ and $u$, parameter used in bond length calculation in various molarity. As a reference, lattice constant of $\mathrm{ZnO}$ from JCPDS 361451 are $\mathrm{a}_{0}=\mathrm{b}_{0}=0.32498 \mathrm{~nm}$ and $\mathrm{c}_{0}=0.52066 \mathrm{~nm}$. Lattice constant of ' $a$ ' and ' $c$ ' of the $\mathrm{ZnO}$ wurtzite structure can be calculated using the relation [14]

$\frac{1}{d^{2} h k l}=\frac{4}{3}\left(\frac{h^{2}+h k+k^{2}}{a^{2}}\right)+\frac{l^{2}}{c^{2}}$

where $d_{h k l}$ represents distance between adjacent planes in the Miller indices $(h k l)$. Parameter of ' $a$ ' and ' $c$ ' are the lattice constant. The lattice constant ' $a$ ' is obtained from plane (100) with relation

$\frac{1}{d^{2}{ }_{100}}=\frac{4}{3}\left(\frac{1}{a^{2}}\right)$

while, the lattice constant ' $c$ ' can be obtained from plane (002) with relation

$\frac{1}{d^{2}{ }_{002}}=\frac{4}{c^{2}}$

From Equation (1), (4) and (5), the lattice constant ' $a$ ' and ' $c$ ' can be derived as

$a=\frac{\lambda}{\sqrt{3} \sin \theta}$

$c=\frac{\lambda}{\sin \theta}$

In order to find the bond length, $L$ of $\mathrm{Zn}-\mathrm{O}$, lattice parameter ' $\mathrm{a}$ ' and ' $c$ ' were used in the relation [16]

$L=\sqrt{\left(\frac{a^{2}}{3}+\left(\frac{1}{2}-u\right)^{2} c^{2}\right)}$

Where,

$u=\frac{a^{2}}{3 c^{2}}+0.25$

Lattice constant of 'a' and 'c', bond length, $L$ and parameter $u$ were summarized in Table 2. Lattice constant, bond length and $u$ parameter were calculated by using Equation (2), Equation (8), 
and Equation (9) respectively. Lattice constant was related to the plane distance of Miller indices plane. Besides, bond length is highly dependent on lattice constant and parameter $u$. Parameter $u$ is related to the ratio of lattice constant ' $a$ ' and ' $c$ '. The lattice constant ' $a$ ' and ' $c$ ' found may be reduced or higher compared to theoretical value found from referred JCPDS (36-1451) due to lattice strain of crystal. In case of lattice constant lower than theoretical, crystalline was compressed and expand if lattice constant is higher. Fig. 3 shows the texture coefficient, TC of peak (100), (002) and (101). In order to calculate the texture coefficient, TC following equation was used [17]

$T C_{(h k l)}=\frac{\frac{I_{(h k l)}}{I_{0(h k l)}}}{\frac{1}{N} \sum_{N}\left(\frac{I_{(h k l)}}{I_{0(h k l)}}\right)}$

where $I_{(h k l)}$ integrated intensities corresponding to plane $(h k l)$ in this study, $I_{0(h k l)}$ is integrated intensities theoretically, and $N$ is the number of diffraction peak. It can be seen that the texture coefficient of plane is increase consistently shows that the crystalline of $\mathrm{ZnO}$ grew with plane (002)-oriented.

Table 2: Lattice constant and bond length, $L$ of based on peak (100), (002) and (101) in different annealing temperatures

\begin{tabular}{|c|c|c|c|}
\hline $\begin{array}{c}\text { Annealing Temperature } \\
\left({ }^{\circ} \mathrm{C}\right)\end{array}$ & $\begin{array}{l}\text { Lattice con- } \\
\text { stant, }(\mathrm{nm})\end{array}$ & $\begin{array}{l}\text { Bond Length, } \\
L(\mathbf{n m})\end{array}$ & $u$ \\
\hline \multirow{2}{*}{300} & $\mathrm{a}=0.3217$ & \multirow{2}{*}{0.1959} & \multirow{2}{*}{0.3794} \\
\hline & $\mathrm{c}=0.5163$ & & \\
\hline \multirow{2}{*}{400} & $\mathrm{a}=0.3220$ & \multirow{2}{*}{0.1960} & \multirow{2}{*}{0.3797} \\
\hline & $c=0.5163$ & & \\
\hline \multirow{2}{*}{500} & $\mathrm{a}=0.3218$ & \multirow{2}{*}{0.1959} & \multirow{2}{*}{0.3799} \\
\hline & $c=0.5155$ & & \\
\hline \multirow{2}{*}{600} & $a=0.3206$ & \multirow{2}{*}{0.1952} & \multirow{2}{*}{0.3798} \\
\hline & $\mathrm{c}=0.5138$ & & \\
\hline \multirow{2}{*}{700} & $a=0.3204$ & \multirow{2}{*}{0.1949} & \multirow{2}{*}{0.3799} \\
\hline & $\mathrm{c}=0.5131$ & & \\
\hline
\end{tabular}

Hsu et al. have been studied the texture coefficient of $\mathrm{ZnO}$ nanostructure grown on PSi [12]. They have suggested that, preferred orientation is exists if the texture coefficient is more than 1. By referring the Equation (4.18), texture coefficients were calculated. In this case, three dominant peaks of (100), (002), and (101) were considered and analyzed. Figure 4.26 shows texture coefficient of $\mathrm{ZnO}$ nanostructures in different annealing temperature. As can be seen in Fig. 3, texture coefficients of (002) is more than 1 and stable except for annealing temperature of $600^{\circ} \mathrm{C}$. This result shows preferred orientation of $\mathrm{ZnO}$ nanostructure growth is plane (002).

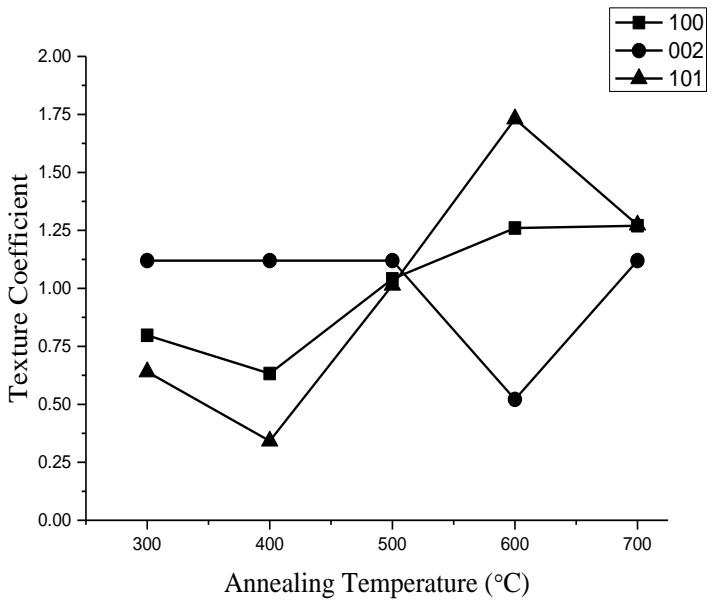

Fig. 3: Texture coefficient of $\mathrm{ZnO}$ nanostructures in different postannealing temperatures of (a) $300{ }^{\circ} \mathrm{C}$, (b) $400{ }^{\circ} \mathrm{C}$, (c) $500{ }^{\circ} \mathrm{C}$, (d) $600{ }^{\circ} \mathrm{C}$ and (e) $700{ }^{\circ} \mathrm{C}$

\section{Conclusion}

$\mathrm{ZnO}$ nanostructures were successfully synthesized using hydrothermal method. Flower-like $\mathrm{ZnO}$ were deposited on PSi at annealing temperature of $500{ }^{\circ} \mathrm{C}$. The crystalline size were found in range of $30.78 \mathrm{~nm}$ to $55.18 \mathrm{~nm}$. Besides, the bond length, $L$ is $0.19 \mathrm{~nm}$. In addition, based on texture coefficient, the preferred orientation of $\mathrm{ZnO}$ nanostructure growth is plane (002).

\section{Acknowledgement}

The authors would like to thank Universiti Teknologi MARA (UiTM) and also Malaysia Ministry of Higher Education for their support and funding from I-Rags Grant, file no: 600-RMI/IRAGS $5 / 3(20 / 2015)$

\section{References}

[1] K. Eswar, J. Rouhi, H. Husairi, M. Rusop, and S. Abdullah, "Annealing heat treatment of $\mathrm{ZnO}$ nanoparticles grown on porous Si substrate using spin-coating method," Advances in Materials Science and Engineering, vol. 2014, 2014.

[2] J. Ghosh, R. Ghosh, and P. K. Giri, "Tuning the visible photoluminescence in $\mathrm{Al}$ doped $\mathrm{ZnO}$ thin film and its application in label-free glucose detection," Sensors and Actuators B: Chemical, vol. 254, pp. 681-689, 2018/01/01/2018.

[3] V. S. Bhati, S. Ranwa, M. Fanetti, M. Valant, and M. Kumar, "Efficient hydrogen sensor based on $\mathrm{Ni}$-doped $\mathrm{ZnO}$ nanostructures by RF sputtering," Sensors and Actuators B: Chemical, 2017/08/18/ 2017.

[4] K. A. Eswar, A. Azlinda, H. F. Husairi, M. Rusop, and S. Abdullah, "Post annealing effect on thin film composed $\mathrm{ZnO}$ nano-particles on porous silicon," Nano Bulletin, vol. 2, p. 130212, 2013.

[5] Y. Feng, G. Wang, J. Liao, W. Li, C. Chen, M. Li, et al., "Honeycomb-like ZnO Mesoporous Nanowall Arrays Modified with Ag Nanoparticles for Highly Efficient Photocatalytic Activity," Scientific Reports, vol. 7, p. 11622, 2017/09/14 2017.

[6] A. Shkurmanov, C. Sturm, H. Franke, J. Lenzner, and M Grundmann, "Low-Temperature PLD-Growth of Ultrathin $\mathrm{ZnO}$ Nanowires by Using $\mathrm{Zn} \times \mathrm{Al1}-\mathrm{x} \mathrm{O}$ and $\mathrm{Zn} \times \mathrm{Ga1}-\mathrm{x}$ O Seed Layers," Nanoscale Research Letters, vol. 12, p. 134, 2017.

[7] K. Eswar, J. Rouhi, F. Husairi, R. Dalvand, S. A. Alrokayan, H. A. Khan, et al., "Hydrothermal growth of flower-like $\mathrm{ZnO}$ nanostructures on porous silicon substrate," Journal of Molecular Structure, vol. 1074, pp. 140-143, 2014.

[8] K. A. Eswar, A. Lepit, R. Rasmidi, F. Husairi, A. Afaah, N. Aadilla, et al., "Seeded Porous Silicon Preparation as a Substrate in the Growth of $\mathrm{ZnO}$ Nanostructures," in Applied Mechanics and Materials, 2015, pp. 626-631.

[9] R. S. Dariani and M. Zabihipour, "Effect of electrical behavior of $\mathrm{ZnO}$ microparticles grown on porous silicon substrate," Applied Physics A, vol. 122, p. 1047, 2016// 2016.

[10] X. T. Zhang, Y. C. Liu, Z. Z. Zhi, J. Y. Zhang, Y. M. Lu, D. Z Shen, et al., "Temperature dependence of excitonic luminescence from nanocrystalline $\mathrm{ZnO}$ films," Journal of Luminescence, vol. 99, pp. 149-154, 2002.

[11] S. K. Min, G. Y. Kwang, L. Jae-Young, K. Soaram, N. Giwoong, Y. K. Do, et al., "Nanocrystalline ZnO Thin Films Grown on Porous Silicon by Sol-gel Method and Effects of Post-annealing," Journal of the Korean Physical Society, vol. 59, p. 346, 2011.

[12] H. C. Hsu, C. S. Cheng, C. C. Chang, S. Yang, C. S. Chang, and W. F. Hsieh, "Orientation-enhanced growth and optical properties of $\mathrm{ZnO}$ nanowires grown on porous silicon substrates," Nanotechnology, vol. 16, pp. 297-301, Feb 2005.

[13] K. Gao, Q. Li, Z. Hu, W. Yu, J. Sun, N. Xu, et al., "Correlation between structure and photoluminescence of $\mathrm{c}$-axis oriented nanocrystalline $\mathrm{ZnO}$ films and evolution of photo-generated excitons," Solar Energy Materials and Solar Cells, vol. 96, pp. 117 123, 2012.

[14] A. Khorsand Zak, W. H. Abd. Majid, M. E. Abrishami, and R. Yousefi, "X-ray analysis of $\mathrm{ZnO}$ nanoparticles by Williamson-Hall and size-strain plot methods," Solid State Sciences, vol. 13, pp. 251-256, 2011.

[15] Z. N. Urgessa, O. S. Oluwafemi, E. J. Olivier, J. H. Neethling, and J. R. Botha, "Synthesis of well-aligned $\mathrm{ZnO}$ nanorods on silicon 
substrate at lower temperature," Journal of Alloys and Compounds, vol. 580, pp. 120-124, 2013.

[16] M. S. Kim, S. Kim, G. Nam, D.-Y. Lee, and J.-Y. Leem, "Effects of growth temperature for buffer layers on properties of $\mathrm{ZnO}$ thin films grown on porous silicon by plasma-assisted molecular beam epitaxy," Optical Materials, vol. 34, pp. 1543-1548, 2012.

[17] M. S. Kim, K. G. Yim, S. Kim, G. Nam, and J.-Y. Leem, "White light emission from nano-fibrous $\mathrm{ZnO}$ thin films/porous silicon nanocomposite," Journal of Sol-Gel Science and Technology, vol. 59, pp. 364-370, 2011. 